\section{NORTH ATLANTIC WEATHER SHIPS}

$D$

RESS reports show that the United States Government has notified the International Civil Aviation Organization of its intention to withdraw the weather ships which it maintains in the North Atlantic when the present international ocean weather ship agreement expires on June 30, 1954.

Ocean weather ships occupy 'fixed' ocean stations and perform several duties. These duties include the making of surface and upper-air meteorological observations at frequent definite intervals and transmitting the data by radio for use in weather forecasting ; navigational aid to aircraft in flight by giving radio bearings and radar fixes, transmitting the latest surface and upper-air observations to aircraft on request and acting generally as relay stations between aircraft and air-traffic control centres ; air-sea rescue duties ; and making oceanographic and other scientific observations as opportunity permits. The ships are located at positions carefully selected for best fulfilment of their meteorological and navigational aid duties from the Norwegian Sea to between the Azores and the United States.

The North Atlantic weather station scheme was arranged at a conference of the International Civil Aviation Organization in 1946 and modified in 1949 by reducing the number of stations from thirteen to ten. The total cost is shared among the participating nations in proportion to the number of flights made across the Atlantic by their civil aircraft.

At present, the United States wholly maintains four stations, the United Kingdom one and Norway with Sweden one. The Netherlands assist in the operation of one station with the United States, one with Great Britain, and one with France; Canada assists the United States in operating one; and certain other nations contribute financially to the scheme. The number of ships needed to man the stations is at least two per station and may be three according to distance from base. The United States employ coastguard cutters, Great Britain and Norway "Flower" class corvettes, and the other participating countries use frigates in the weather ship service.

Besides those in the North A.tlantic, the United States, Canada, and Japan maintain weather ships in the North Pacific under an entirely separate arrangement.

The cessation of reports from the American weather ships would handicap weather forecasters working for the North Atlantic air routes mainly by the loss of upper-air information. Location of the often rather narrow belts of high wind, the so-called jetstreams, which may seriously increase the flighttimes of aircraft flying against them, is a matter of much concern to the North Atlantic forecaster. Pre-flight planning of the fuel to be carried by trans-Atlantic aircraft is based on the forecast upper winds. To obtain the same degree of safety with less certain knowledge of the winds to be expected would necessarily mean on many occasions that airlines would have to sacrifice paying load to carry more fuel as an insurance against the increased risk of encountering headwinds stronger than forecast. This would be a direct financial loss to the airlines of all countries concerned in North Atlantic flying.

Valuable observations are regularly made and transmitted by voluntary observers on merchant ships, but not so frequently as by the meteorologists on weather ships, and, in particular, they include no upper-air observations. Merchant ships are, of course, almost always moving, and even with the good organization in force for collecting their reports, large areas without observations on the weather maps are inevitable.

Apart from the immediate use of weather ship observations in forecasting, the detailed logs are interchanged among the nations for the building up of a comprehensive climatology of the North Atlantic from the surface to heights of more than $50,000 \mathrm{ft}$. Never before have continuous weather records from fixed ships in mid-ocean been obtained. Further, the ships provide admirable laboratories for special investigations in oceanography and other geophysical subjects, and small expeditions from university research institutes have worked in them.

It is to be hoped that a new agreement providing for the maintenance of some, at least, of the American stations will be reached before the present one expires.

\section{A WHALE-MARKING EXPEDITION}

By DR. N. A. MACKINTOSH, C.B.E.

National Institute of Oceanography, Wormley, Surrey

THE marking of whales can assist nearly all investigations on the populations and life-cycle of whales, it seems the only satisfactory method of gaining information on many aspects of their distribution and movements, and it was carried out on a considerable scale by the Discovery Committee before the Second World War. A previous article in Nature $^{1}$ gave a summary of the information already obtained from recovered marks, and directed attention to the need for more marking, both in the Antarctic and in other regions. It was noted that the National Institute of Oceanography (which now includes the Discovery Investigations) could not now meet the cost of special marking expeditions; but the hope was expressed that some means of continuing the work would be found.

The generosity of a number of whaling companies has now led to such an expedition, and a ship is on the way to the Antarctic to mark whales during some weeks immediately before the opening date (January 2) of the whaling season of 1954. The marking has been organized jointly by the National Institute of Oceanography and the Norwegian State Institute for Whale Research.

The importance of whale marking had been endorsed at recent meetings of the International Whaling Commission, and after correspondence with the National Institute the former chairman of the Commission (Ambassador B. Bergersen) and the secretary of the Association of Whaling Companies (Mr. E. Vangstein) took the initiative in approaching the whaling companies. In the summer of $1953 \mathrm{a}$ number of these companies (British, Norwegian, Dutch and South African) agreed to share the cost of about a month's marking by the modern whale catcher Enern, owned by the Norwegian company, A/S Thor Dahl. Whale catchers hitherto had not been the ideal ships for whale marking on account of their relatively short cruising range, which tended to restrict marking to the immediate field of hunting. But the Enern is a powerful new diesel-driven vessel with a cruising-range which enables her to sail more than a month in advance of the parent factory ship, from which catchers are normally refuelled. 